\title{
A STUDY AND REVIEW OF NON-SURGICAL CAUSES OF PNEUMOPERITONEUM (SPONTANEOUS PNEUMOPERITONEUM) IN TERTIARY CARE CENTRE, GOVERNMENT VELLORE MEDICAL COLLEGE HOSPITAL, VELLORE
}

\author{
Soundarapandiyan $R^{1}$, Loganathan $D^{2}$, Udhayasankar $V^{3}$ \\ 1 Professor, Department of General Surgery, Government Vellore Medical College, Vellore, Tamilnadu. \\ 2 Professor, Department of General Surgery, Government Vellore Medical College, Vellore, Tamilnadu. \\ 3Junior Resident, Department of General Surgery, Government Vellore Medical College, Vellore, Tamilnadu.
}

\section{ABSTRACT}

\section{BACKGROUND}

Air in the peritoneal cavity is called as Pneumoperitoneum. Not all the cases of pneumoperitoneum are due to hollow viscus perforation. Most common cause of pneumoperitoneum is due to hollow viscus perforation in $90 \%$ cases, mostly due to duodenal ulcer perforation or gastric perforation. In $10 \%$ of the cases, the pneumoperitoneum does not indicate the perforation nor warranted the surgery. Pneumoperitoneum that is non-iatrogenic that does not need surgery is called as spontaneous pneumoperitoneum.

\section{MATERIALS AND METHODS}

This study analyses the spontaneous/non-surgical causes of pneumoperitoneum and our experience in our institute for the past 5 years that is from June 2011 to May 2016 and also aims to create awareness about the non-surgical causes of pneumoperitoneum, identifying cases for which negative laparotomy can be avoided.

\section{RESULTS}

In this period 11 patients were identified with nonsurgical causes of pneumoperitoneum, from that 2 patients underwent emergency laparotomy which was negative and 9 patients were managed conservatively.

\section{CONCLUSION}

In our study totally 11 patients were presented with pneumoperitoneum, out of which 9 patients were managed conservatively and 2 patients underwent negative laparotomy. Most common cause of spontaneous pneumoperitoneum in our study is thoracic cause.

\section{KEYWORDS}

Spontaneous Pneumoperitoneum, Non-Surgical Causes of Pneumoperitoneum.

HOW TO CITE THIS ARTICLE: Soundarapandiyan R, Loganathan D, Udhayasankar V. A study and review of non-surgical causes of pneumoperitoneum (spontaneous pneumoperitoneum) in tertiary care centre, Government Vellore Medical College Hospital, Vellore. J. Evolution Med. Dent. Sci. 2016;5(96):7052-7055, DOI: 10.14260/Jemds/2016/1595

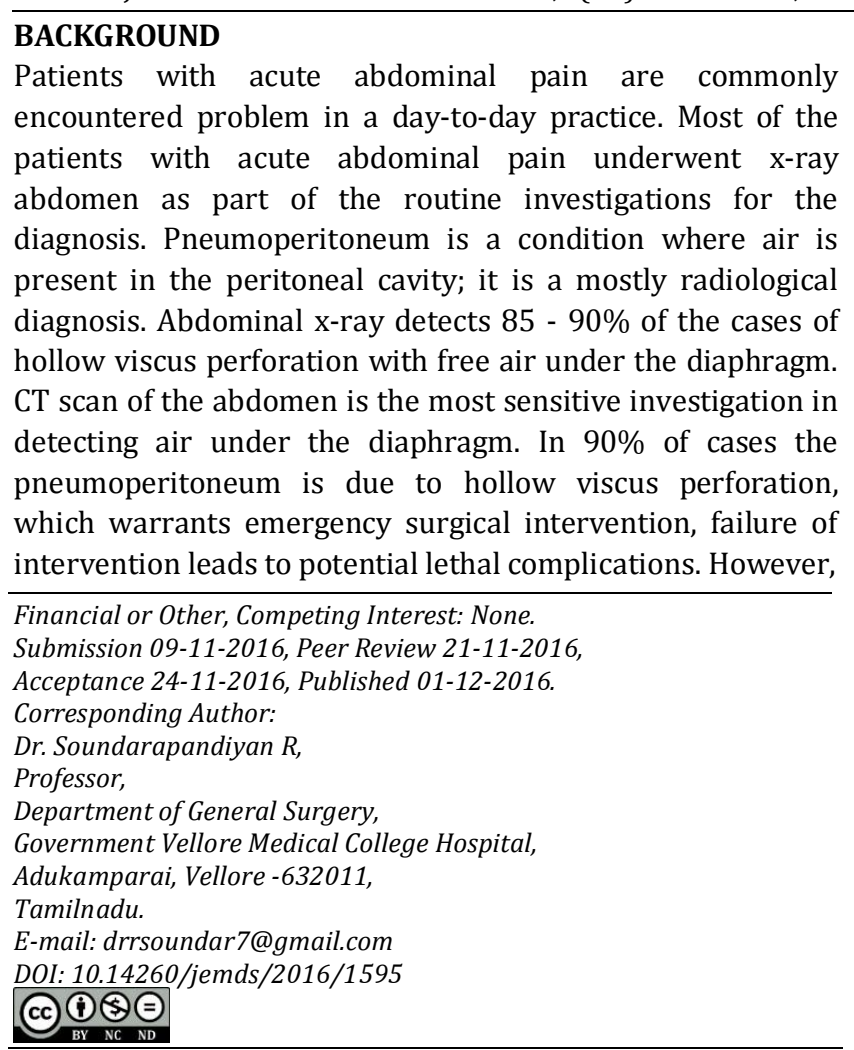
not all the cases of pneumoperitoneum is due to hollow viscus perforation. In $10 \%$ of cases, there was no identifiable such cause was found called as spontaneous pneumoperitoneum or non-surgical pneumoperitoneum. ${ }^{1}$ The term spontaneous or non-surgical pneumoperitoneum was found since the first description of pneumoperitoneum on abdominal x-ray.

Even now-a-days not all the physicians are aware of the entity called spontaneous pneumoperitoneum and often unnecessary laparotomy can be avoided.

\section{Objectives of the Study}

1. This study analyses cases of the Negative Laparotomy with no surgical cause.

2. Review the causes of non-surgical pneumoperitoneum.

3. To identify the cases of pneumoperitoneum for which negative laparotomy can be avoided.

\section{MATERIALS AND METHODS} Study Design

This study is undertaken in the patients with pneumoperitoneum in Government Vellore Medical College, Vellore for the period from June 2011 to May 2016, which is taken as retrospective study. 
Inclusion Criteria as illustrative cases from GVMCH, Vellore.

1. Successful management by observation and supportive care without surgical intervention was defined as the diagnostic feature of non-perforation.

2. Failure of a laparotomy to delineate a surgical cause or to result in a reparative procedure is congruent with a nonsurgical cause of pneumoperitoneum.

\section{Exclusion Criteria}

Patients with pneumoperitoneum with identifiable cause.

\section{RESULTS}

For the above period, 11 cases were observed. Out of the 11 cases 2 cases underwent laparotomy, which shows no evidence of perforation. Out of the 11 cases, 9 patients were males and 2 patients were females.

\begin{tabular}{|c|c|c|c|c|c|}
\hline Age/Sex & Patient Complaint & Past History & X-Ray & Management & $\begin{array}{c}\text { Followup after } \\
2 \text { Weeks }\end{array}$ \\
\hline $\begin{array}{c}54 \\
\text { yrs } / M\end{array}$ & Epigastric Pain & Tuberculosis & Pneumoperitoneum & $\begin{array}{l}\text { Laparotomy - } \\
\text { Negative }\end{array}$ & - \\
\hline $\begin{array}{c}70 \\
\mathrm{yrs} / \mathrm{M}\end{array}$ & Diffuse Abdominal Pain & COPD & Pneumoperitoneum & Conservative & Air disappears \\
\hline $\begin{array}{c}65 \\
\mathrm{yrs} / \mathrm{M}\end{array}$ & $\begin{array}{l}\text { On Mechanical } \\
\text { Ventilator }\end{array}$ & $\begin{array}{c}\text { COPD/ } \\
\text { Respiratory } \\
\text { failure }\end{array}$ & Pneumoperitoneum & Conservative & Air disappears \\
\hline $\begin{array}{c}55 \\
\mathrm{yrs} / \mathrm{M}\end{array}$ & $\begin{array}{l}\text { Abdominal Pain with } \\
\text { F/O Peritonitis }\end{array}$ & $\begin{array}{l}\text { HIV } 1 \text { positive, } \\
\text { K/C PT }\end{array}$ & Pneumoperitoneum & $\begin{array}{l}\text { Laparotomy - } \\
\text { Negative }\end{array}$ & - \\
\hline $35 \mathrm{yrs} / \mathrm{F}$ & Nil & $\begin{array}{l}\text { Gynaecologic } \\
\text { examination }\end{array}$ & Pneumoperitoneum & Conservative & Air disappears \\
\hline $\begin{array}{c}64 \\
\text { yrs } / M\end{array}$ & Difficulty in Breathing & COPD & Pneumoperitoneum & Conservative & Air disappears \\
\hline $\begin{array}{c}67 \\
\mathrm{yrs} / \mathrm{M}\end{array}$ & Abdominal pain & - & Pneumoperitoneum & Conservative & Air disappears \\
\hline $42 \mathrm{yrs} / \mathrm{F}$ & Difficulty in Breathing & Scleroderma & Pneumoperitoneum & Conservative & Air disappears \\
\hline $\begin{array}{c}61 \\
\mathrm{yrs} / \mathrm{M}\end{array}$ & $\begin{array}{l}\text { Post CPR for cardiac } \\
\text { arrest in case of IHD }\end{array}$ & HT, DM,IHD & Pneumoperitoneum & Conservative & $\begin{array}{c}\text { Patient } \\
\text { Expired } \\
\text { After } 2 \text { days } \\
\end{array}$ \\
\hline $\begin{array}{c}69 \\
\text { yrs } / M\end{array}$ & Abdominal pain & COPD & Pneumoperitoneum & Conservative & Air disappears \\
\hline $\begin{array}{c}72 \\
\mathrm{yrs} / \mathrm{M}\end{array}$ & Trauma & PT & $\begin{array}{l}\text { Pneumoperitoneum, } \\
\text { Rt Pneumothorax and } \\
\text { Pneumomediastinum }\end{array}$ & $\begin{array}{l}\text { Conservative } \\
\text { ICD done }\end{array}$ & Air disappears \\
\hline
\end{tabular}

Table 1 depicts the patients presenting, the age and sex distribution of the patients, patients presenting complaint to the hospital and past history, management and followup.

\begin{tabular}{|c|c|c|c|c|}
\hline Sl. No. & Age/Sex & Associations & Cause & Category \\
\hline 1. & 54 yrs./M & Tuberculosis & Increased Intrathoracic Pressure & Thoracic \\
\hline 2. & 70 yrs./M & COPD & ? Bullous Rupture & Thoracic \\
\hline 3. & $65 \mathrm{yrs} . / \mathrm{M}$ & On Mechanical Ventilator & IPPV & Thoracic \\
\hline 4. & 55 yrs./M & HIV 1 Positive, Tuberculosis & Pneumatosis Cystoides Intestinalis (PCI) & Abdominal \\
\hline 5. & 35 yrs./F & Gynaecologic Examination & Air Insufflation & Pelvic \\
\hline 6. & 64 yrs./M & COPD & Increased Intrathoracic Pressure & Thoracic \\
\hline 7. & 67 yrs./M & ? Peptic Ulcer Disease & Subclinical perforation & Abdominal \\
\hline 8. & 42 yrs./F & Scleroderma & Collagen Vascular Disease with? PCI & Abdominal \\
\hline 9. & 61 yrs./M & Post CPR & $\mathrm{CPR}$ & Thoracic \\
\hline 10. & 69 yrs./M & COPD & Increased Intrathoracic Pressure & Thoracic \\
\hline 11. & 72 yrs. $/ \mathrm{M}$ & Trauma & Trauma & Thoracic \\
\hline
\end{tabular}

Table 2 shows out of the 11 cases, we observed 7 cases belongs to the category of Thoracic and 3 cases to the Abdominal and one patient to the Pelvic that is gynaecologic.

\section{DISCUSSION}

Spontaneous pneumoperitoneum has many number of causes, which is listed below as table in Table 3.

\begin{tabular}{|c|c|}
\hline Category & Mechanism \\
\hline Postoperative & Retained air from open laparotomy \\
\hline & Retained air from laparoscopy \\
\hline Thoracic & Intermittent positive-pressure ventilation \\
\hline
\end{tabular}

\begin{tabular}{|c|c|}
\hline & Barotrauma \\
\hline & $\begin{array}{c}\text { Increased intrathoracic pressure - cough, } \\
\text { retching }\end{array}$ \\
\hline & Valsalva manoeuvre \\
\hline & Asthma \\
\hline & Bronchoscopy \\
\hline & Cardiopulmonary resuscitation and \\
\hline & mouth-to-mouth ventilation \\
\hline & Adenotonsillectomy \\
\hline
\end{tabular}




\begin{tabular}{|c|c|}
\hline & Pulmonary tuberculosis \\
\hline & Blunt trauma \\
\hline & Bronchopulmonary fistula \\
\hline & Spontaneous rupture of pulmonary blebs \\
\hline Abdominal & Pneumatosis cystoides intestinalis \\
\hline & Post-polypectomy syndrome \\
\hline & Peritoneal dialysis \\
\hline & Collagen vascular disease \\
\hline & Pneumocholecystitis \\
\hline & Jejunal and sigmoid diverticulosis \\
\hline & Distended hollow viscus \\
\hline Gynaecologic & Subclinical perforated viscus \\
\hline & Vaginal insufflation \\
\hline & Knee-chest exercises \\
\hline & Pelvic inflammatory disease \\
\hline & Coitus \\
\hline & Gynaecologic examination procedures \\
\hline Idiopathic & Vaginal douching \\
\hline Table 3. Causes of Spontaneous Pneumoperitoneum ${ }^{2,3}$ \\
\hline
\end{tabular}

\section{Post-Operative}

Free air in the peritoneal cavity following an abdominal procedure is an expected occurrence. Usually, the free air following procedure completely absorbed within a week's time (7 days), but may persist as long as 4 weeks and detected on x-rays.

So in a patient with abdominal pain, recent history of abdominal or pelvic surgical history to be elicited. In a case of air due to postoperative, decreasing amount of air is expected. But in case of hollow viscus perforation, protracted increasing amount of air is present.

\section{Thoracic}

Intrathoracic causes are most frequent cause of spontaneous/non-surgical pneumoperitoneum.

\section{In Patients with Intermittent Positive-Pressure Ventilation}

Air is directly introduced into peritoneal cavity through microscopic defects in pleura and diaphragm, which causes free air in the peritoneal cavity.

In patients with mechanical ventilator risk of pneumoperitoneum is increased if the Positive Inspiratory Pressure is $>40 \mathrm{~cm} \mathrm{H}_{2} \mathrm{O}$ and Peak End expiratory pressure is more than $6 \mathrm{~cm} \mathrm{H}_{2} \mathrm{O}^{4}$. In a case of COPD the mechanism through which pneumoperitoneum occurs is rupture of alveoli, it causes free alveolar air which in turn produces air entering into the mediastinum; from there air enters into the retroperitoneum along the perivascular sheaths work done by Macklin. From the retroperitoneum, it ruptures into the peritoneal cavity producing the pneumoperitoneum.

In trauma any condition causing increase in intrathoracic pressure leads to pneumoperitoneum, which is a surgical dilemma, absence of associated clinical signs for intraabdominal pathology or contrast radiological studies to rule out enteric perforation, helpful for the conservative management of the patient.

In mouth-to-mouth, the pneumoperitoneum caused through increased tracheal pressure. In cardiopulmonary resuscitation, the pneumoperitoneum caused through increased airway pressure and blunt force to the chest.

\section{Pneumatosis Cystoides Intestinalis}

Pneumatosis cystoides intestinalis probably accounts for a significant proportion of those abdominal causes of pneumoperitoneum not resulting from a ruptured abdominal viscus. First pathologic description by DuVernoi from a cadaver dissection in 1730 . The condition was characterised by multiple intramural gas-filled cysts, seen throughout the GIT, commonly in terminal ileum. This condition is benign and asymptomatic, presents with nonspecific complaints such as vomiting, nausea, etc. The mechanism of submucosal rupture of free air produces intraperitoneal free air with or without features of peritonitis associated with chronic obstructive pulmonary disease and inflammatory bowel disease. ${ }^{5}$ It resolves spontaneously mostly. In immunosuppressed individuals, enteric infection, bowel ischaemia or death can occur.

Other rare causes includes pneumocholecystitis, jejunal and sigmoid diverticulosis, distended hollow viscus. The mechanism for the rare causes, thinned intact bowel wall with increased lumen pressure the air escapes into the peritoneal cavity, produces the pneumoperitoneum.6,7,8 Subclinical perforations allows air to escape through the microperforations without spillage of enteric contents.

\section{Gynaecologic Causes}

Vaginal insufflations, coitus, vaginal douching the air is entered into the peritoneal cavity via fallopian tubes, the pneumoperitoneum without the signs of peritonitis will be present. $^{9}$

To distinguish spontaneous pneumoperitoneum from surgical cause of pneumoperitoneum, the following algorithm is presented.

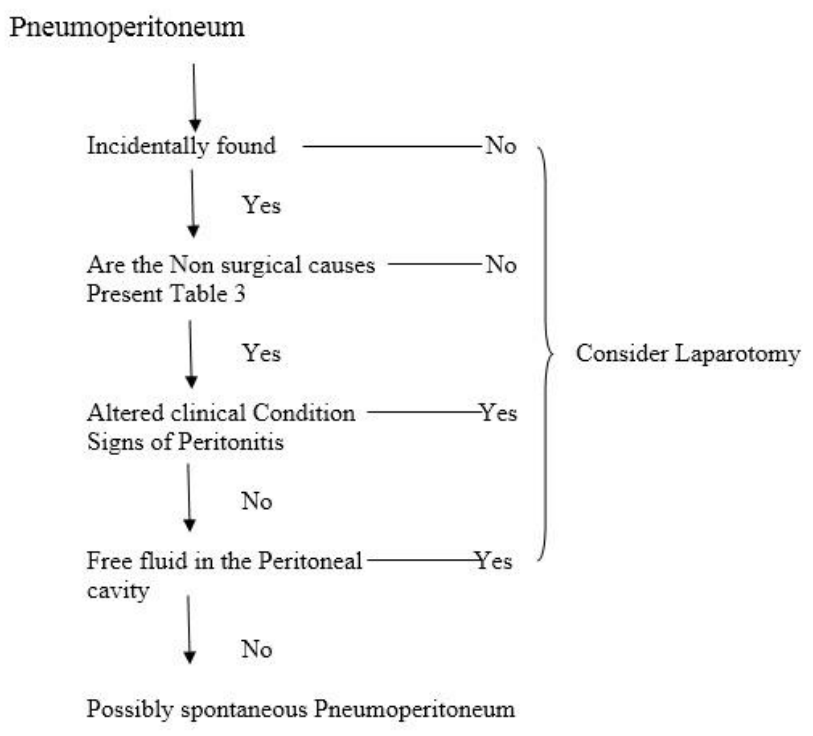

Possibly spontaneous Pneumoperitoneum.
Indications for Laparotomy in Patients with Spontaneous Pneumoperitoneum
- Onset of abdominal pain.
- Peritonism/peritonitis.
- Tachycardia/Hypotension.
- Rising white cell count. 
- Radiology suggests free enteric leak.

- Failure of conservative management.

\section{CONCLUSION}

In our study totally 11 patients were presented with pneumoperitoneum, out of which 9 patients were managed conservatively, 2 patients underwent negative laparotomy. Most common cause of spontaneous pneumoperitoneum in our study is thoracic cause.

Spontaneous pneumoperitoneum is an uncommon wellknown entity with number of causes. Although in majority of the patients with pneumoperitoneum is due to hollow viscus perforation, which requires laparotomy. The high index of suspicion is needed if the enumerated causes of pneumoperitoneum is present, in whom the patients not having features of peritonitis. These patients are managed conservatively with followup. If any evidence of clinical deterioration, patient needs laparotomy.

\section{REFERENCES}

1. Miller RE, Nelson SW. The roentgenologic demonstration of tiny amounts of free intraperitoneal gas: experimental and clinical studies. Am J Roentgenol Radium Ther Nucl Med 1971;112(3):574-85.
2. Hillman KM. Pneumoperitoneum - a review. Crit Care Med 1982;10:476-81.

3. Mularski RA, Sippel JM, Osborne ML. Pneumoperitoneum: a review of nonsurgical causes. Crit Care Med 2000;28(7):2638- 44.

4. Mularski RA, Ciccolo ML, Rappaport WD. Nonsurgical causes of pneumoperitoneum. West J Med 1999;170(1):41-6.

5. Pieterse AS, Leong AS, Rowland R. The mucosal changes and pathogenesis of pneumatosiscystoidesintestinalis. Hum Pathol 1985;16(7):683-8.

6. Schwessinger WH, Levinc BA, Ramos R. Complications in colonoscopy. Surg Gynecol Obstet 1979;148(2):270-81.

7. Dunn V, Nelson JA. Jejunal diverticulosis and chronic pneumoperitoneum. Gastrointest Radiol 1979;4(2):165-8.

8. Hirano $\mathrm{Y}$, Hara $\mathrm{T}$, Nozawa $\mathrm{H}$, et al. Asymptomatic spontaneous pneumoperitoneum complicating duodenal diverticulum. Indian J Surg 2006;68(2):99-101.

9. Madura MI, Craig RM, Shields TW. Unusual causes of spontaneous pneumoperitoneum. Surg Gynecol Obstet 1982;154(3):417-20. 